\title{
MÚSICOS DO NORDESTE NO VALE DO PARAÍBA: TRAJETÓRIAS MUSICAIS E PLURALIDADE DA EXPERIÊNCIA NORDESTINA
}

\author{
Lucas Pulice $^{1}$ \\ Valéria Barbosa de Magalhães ${ }^{2}$
}

\section{RESUMO:}

Este artigo aborda a ideia de identidade nordestina entre musicistas que nasceram em diferentes estados do Nordeste e que hoje trabalham em São José dos Campos (SP). Tendo por base as carreiras no Sudeste, analisamos sua relação ou não com os chamados ritmos nordestinos e as influências musicais ao longo das suas trajetórias. Procurou-se saber se a identidade nordestina é acionada ou não em sua arte e de que forma. O texto assume que a ideia de Nordeste é problemática. A pesquisa utilizou entrevistas de história oral temática.

Palavras-chave: Nordeste. Trajetórias musicais. Migrações do Nordeste para o Sudeste. História Oral.

\begin{abstract}
:
This article discusses how musicians from different states in Northeastern Brazil have conducted their careers in São José dos Campos in São Paulo, considering their northeastern rhythms background. We also consider their musical influences along their trajectory. The work tries to understand whether their northeastern identity had influenced or not their careers. The research was based on oral history interviews with musicians from the Brazilian Northeast who have migrated to the Vale do Paraiba.
\end{abstract}

Key Words: Brazilian Northeastern. Musicians life stories. Migration. Oral history.

1 Mestre em Filosofia/USP, bacharel em Marketing/USP e pesquisador do GEPHOM/USP. gephom@ gmail.com. 2 Professora da EACH/USP. Orientadora na Pós-Graduação em Estudos Culturais/USP. Doutora em História Social. Coordenadora do GEPHOM/USP. gephom@gmail.com. 
Diante da imprecisão do conceito de Nordeste, cabe a este trabalho contribuir para os debates acerca do tema. A pesquisa aqui apresentada buscou aprofundar discussões importantes no campo da música, especialmente no cenário musical no âmbito joseense, em questões acerca da música como carreira profissional no Brasil e no mercado de trabalho para musicistas ${ }^{3}$. Cada entrevistado ou entrevistada apresentou trajetória única, deixando evidente a pluralidade de histórias de vida dos nordestinos migrantes, assim como a heterogeneidade musical entre os estados.

A metodologia utilizada no trabalho foi a história oral. Foram entrevistado(a)s oito musicistas, um radialista da cena musical joseense (todos nordestino/as) e um musicista nãonordestino, estudioso do tema. Da viola à bateria, do trompete ao baixo elétrico, com diferentes sotaques, os entrevistados e entrevistadas apresentam trajetórias diversas. Suas atuações musicais transitam por diversos gêneros, reafirmando a heterogeneidade e pluralidade do Nordeste, contrariamente aos estereótipos e construções imagético-discursivas normalmente sedimentadas sobre a região.

Este artigo tem o objetivo de entender como musicistas que nasceram em diferentes estados do Nordeste conduziram sua carreira em São José dos Campos (SP), levando em conta a relação ou não com os chamados ritmos nordestinos, as influências musicais ao longo da sua trajetória, se a identidade nordestina foi acionada ou não em sua carreira e em quais momentos.

\section{Nordeste(s) nas trajetórias musicais}

Desde cedo, assimilamos naturalmente o termo "Nordeste". Mas que Nordeste? Se ele abarca tantos estados diferentes, com culturas diversas, por que vemos frequentemente uma representação universal e estereotipada do Nordeste e dos nordestinos?

Durval Albuquerque Jr. foi um dos primeiros autores a encabeçarem essa discussão. Segundo ele (2009), em canais de comunicação brasileiros, como jornais ou emissoras de televisão, há um discurso enraizado em estratégias de estereotipação sobre o Nordeste. Assim, os estereótipos do "diferente" reafirmam a superioridade do "normal".

\footnotetext{
${ }^{3} \mathrm{O}$ artigo, concebido em coautoria entre orientadora e orientado, apresenta reflexões conjuntas sobre os dados da pesquisa de Lucas Pulice, intitulada Timbres em trânsito: um estudo sobre identidades, Nordestes e música em São José dos Campos, defendida, em 2019, no Programa de Pós-Graduação em Estudos Culturais/USP e orientado por Valéria B. Magalhães. As entrevistas aqui referidas foram conduzidas por Lucas, durante seu mestrado.
} 
A criação de sentidos na estereotipação é um mecanismo de dominação, impedindo a relação original que poderia haver entre indivíduos de diferentes grupos sociais, não fossem os estereótipos. Albuquerque (2009) argumenta que as imagens e discursos acerca do Nordeste são consequência de relações de poder que precisam ser investigadas:

Como foi construído esse repertório de reproduções sobre o Nordeste? Sempre foi assim? Por quais caminhos se construiu o Nordeste?

Analisando composições atuais de nordestinos que migraram durante suas carreiras, encontramos discursos que se posicionam próximos aos dois polos (e que podem transitar entre eles): os que buscam se distanciar do estereótipo de nordestino e os que buscam valorizar a ideia de Nordeste. Esses polos se misturam em uma linha tênue e podem soar contraditórios. Dois exemplos de trechos de músicas do rapper Don $L$, de Fortaleza (SP), que atualmente vive em São Paulo, são ilustrativos desse dilema:

E eu deixei o Nordeste / Há dois anos com uma sede de secar a Sabesp / Sem chapéu de palha, nada clichê e velho / Eu vim pra tomar o jogo / Não pra ser um boneco exótico ${ }^{4}$.

Eu lembro do Caetano me entregar um prêmio / De melhor do Nordeste / O que diz sobre isso / Porque não tinha uma categoria pro Sul / Então era tipo / Esmola pra segunda divisão ${ }^{5}$.

No primeiro trecho, o músico faz referência à seca nordestina, a qual está presente nos estereótipos recorrentes sobre a região, e critica a ideia de nordestino como exótico. A segunda parte ironiza um episódio em que o grupo de rap que integrava, o Costa a Costa, havia ganhado o Prêmio Hutúz 2009 na categoria Norte-Nordeste. Caetano Veloso foi chamado para entregar o prêmio. Paralelamente aos latinos, que raramente ganham o Grammy "oficial”, foi criada uma categoria Norte-Nordeste para o prêmio, dando a entender que o prêmio principal é destinado ao eixo Sudeste. Ou seja: mesmo Caetano sendo uma figura importante para a quebra de estereótipos do Nordeste desde o Movimento Tropicalista (e que é muito admirado pelo Don $L$ ), acabou participando de um evento que reforçou o regionalismo e a segregação Nordeste $x$ Sul.

\footnotetext{
${ }^{4}$ DON L. Eu não te amo. São Paulo: Don L Music: 2017.

Disponível em: 〈https://www.youtube.com/watch?v=FmXIiQBmW18〉. Acesso em: 5 dez. 2019.

${ }^{5}$ DON L. Fazia sentido. São Paulo: Don L Music: 2017.

Disponível em: <https://www.youtube.com/watch?v=aGBeBHo7A8g>. Acesso em: 5 dez. 2019.
} 
Gerações e gerações seguem presas a temas e discursos imagéticos do Nordeste impulsionados na década de 1920 com Gilberto Freyre, José Lins do Rego e outros - ligados à miséria e à injustiça social. A região é imaginada como local de resistência à modernidade, dos coronéis e dos seres humanos rústicos e brutos. Autores como Jorge Amado, Graciliano Ramos e João Cabral de Melo Neto são exemplos que reforçam a imagem de nordestinos como vítimas e passivos diante do desenvolvimento do país, ideia ainda cultivada por pessoas do campo da cultura no século XXI, quase cem anos depois.

A região Nordeste é, na maioria das vezes, pensada como rural e atrasada, mesmo tendo algumas das maiores cidades do país. Suas produções artísticas e científicas são negligenciadas (ALBUQUERQUE, 2009). Ainda que com a desculpa de valorizar sua riqueza cultural, essas ideias favoreceram sua marginalização e reforçam a ideia de isolamento diante do desenvolvimento modernista do país.

Felipe Trotta (2012) discute as complexidades da construção da identidade nordestina na música pensando no sucesso de Luiz Gonzaga e na sua grande exposição nacional. A música nordestina passa então a ser assimilada diretamente ao forró, ao baião e ao universo cabramacho, valores assumidos como coletivos. $\mathrm{O}$ autor mostra que, mesmo com a des-sanfonização do forró e a busca por uma estética mais pop e jovem, o valor da bravura e macheza permanecem. (TROTTA, 2012).

Os estereótipos do músico nordestino do baião, com suas indumentárias sertanejas ou então o imaginário em torno do universo folclórico, de culturas tradicionais, são imagens e discursos que acompanham musicistas que tenham nascido em algum estado do Nordeste e que migraram para o Centro-Sul do país.

André Leano, de Fortaleza (CE), ao chegar em São José dos Campos, deparou-se com músicos que tinham a expectativa de que ele soubesse tocar frevos e ritmos de Pernambuco:

Então não é comum, por exemplo, o cearense tocar bem o frevo por exemplo. Só quem tá ali no interior perto, mas até quando eu cheguei aqui o pessoal pensa que eu: "ah, toca bem frevo, você é do frevo". (ANDRÉ LEANO) $)^{6}$.

\footnotetext{
${ }^{6}$ Entrevista de André Leano, concedida a Lucas Pulice, em 11 de maio de 2018.
} 
Baiano, Marquinho da Luz é percussionista, baterista e toca vibrafone. Aos onze anos de idade começou a tocar em um grupo de samba com amigos de infância. Após alguns anos, passou a tocar em um grupo de percussão patrocinado pelo Serviço Social do Comércio (SESC) já de forma mais profissional. Depois, Marquinho se envolveu em diversos outros projetos em Salvador e, com dezesseis anos de idade, estava tocando em apresentações do consagrado grupo de percussão Timbalada. Aos dezoito anos, foi para São José dos Campos por conta de uma oportunidade musical e resolveu ficar mais tempo. Na cidade, o músico atuou em bandas de diferentes estilos, desde instrumentais até voltadas para o entretenimento em festas e bares. Ao longo de sua trajetória, Marquinho tocou, por exemplo, em trios elétricos de carnaval, banda de casamento, grupos de jazz e atualmente faz turnês com a internacionalmente renomada rede de circos canadense Cirque du Soleil.

Por ser baterista e percussionista, sua formação e experiência proporcionaram boa reflexão sobre os ritmos brasileiros. Ao ser perguntado sobre a música nordestina respondeu:

É muito separada. É muito mesmo, assim. Quem é nordestino sabe. Porque, no meu caso, eu sou baiano, então a música... a música baiana... eu posso falar do forró. O forró baiano pro forró de Pernambuco é diferente. E são detalhes que só quem é nordestino... É que nem idiomas: quando você aprende assim é... o cara que é nativo ele sabe, ele de longe sabe quem fala a língua dele. E quem é de fora às vezes não percebe os mínimos detalhes (...) só quem nasce lá mesmo pra perceber, a diferença nos ritmos... (MARQUINHOS DA LUZ) ${ }^{7}$.

Rebeca Costa, outra entrevistada, também chama a atenção para essa diversidade dentro do Nordeste e as diferenças entre estados:

É, tem muita coisa, né? Aprender a conviver com isso, com toda essa diversidade que tem no Brasil é muita coisa. É o que eu falei: só na minha terra, só em Pernambuco, tem não sei quantos ritmos que às vezes eu falo aqui e o pessoal: "não conheço", "desconheço"... caboclinho, maracatu, tem o cavalomarinho, tem o coco, tem a ciranda, e isso só, só no meu estado. (REBECA $\operatorname{COSTA})^{8}$

\footnotetext{
${ }^{7}$ Entrevista de Marquinho da Luz, concedida a Lucas Pulice, em 4 de fevereiro de 2019.

${ }^{8}$ Entrevista de Rebeca Costa, concedida a Lucas Pulice, em 11 de maio de 2018.
} 
As declarações de Marquinho da Luz e de Rebeca Costa desmontam o estereótipo sobre o nordestino que frequentemente é acionado e reproduzido. Daniel Saraiva (2017) mostra, por exemplo, diferenças entre Luiz Gonzaga e uma geração de músicos nordestinos que ganhou destaque a partir da década de 1970. Em pesquisa sobre Terezinha de Jesus (Florânia, RN), Jorge Mello (Piripiri, PI) e Téti (Quixadá, CE), Saraiva aponta diferenças que se refletem em suas próprias composições:

O lugar de pertencimento fez com que esses artistas cantassem um Nordeste diferente daquele cantado por Gonzaga. Mais urbanizado, suas letras não evocam tanto o cotidiano sofrido do nordestino. Jorge Mello cursou Direito e Téti não entrou na universidade, mas estava sempre presente no meio universitário acompanhando seu marido Rodger, músico e professor da Universidade Federal do Ceará (UFC). Terezinha de Jesus entrou em Serviço Social na Universidade Federal do Rio Grande do Norte (UFRN), que cursou por dois anos antes de pedir transferência para a Universidade Estadual do Rio de Janeiro (UERJ), onde trocou de curso e se tornou licenciada em Música. Os três, ao mesmo tempo em que são do interior, tiveram uma formação nos grandes centros de suas regiões. Em seus discos é possível ver a mistura do sertão com o cotidiano urbano, justamente o que tinham de vivência. (SARAIVA, 2017, p. 141).

Do ponto de vista do Sudeste há uma cultura musical nordestina imaginada e que, até certo ponto, foi reforçada por ícones como Luiz Gonzaga. Portanto, em vez de reforçar discursos de homogeneização do Nordeste, se faz necessário o esforço em disseminar a heterogeneidade da região. $\mathrm{E}$, ao que parece, os músicos entrevistados têm contribuído para esse esforço no sentido de mostrar que cultura nordestina é plural.

Analisemos o relato de Nathalia Ferro, que é maranhense:

(...) na verdade, o Maranhão ele é muito meio Norte, eu tô aqui falando pelo Nordeste, mas o fato é que a gente também é muito influenciada pela música do Pará ali, a gente tá tal qual, entendeu? (NATHÁLIA FERRO) ${ }^{9}$.

A fala de Nathalia Ferro aponta uma fluidez, inclusive das fronteiras entre regiões, dizendo que o Maranhão tem fortes sonoridades musicais ligadas ao Estado do Pará, localizado na região Norte do Brasil. Sendo assim, a ideia de heterogeneidade entre os estados que

\footnotetext{
${ }^{9}$ Entrevista de Nathalia Ferro, concedida a Lucas Pulice, em 5 de novembro de 2018.
} 
compõem o Nordeste segue afirmada por esses músicos. Afinal, na Bahia, por exemplo, que fica muito distante do Pará, essas conexões culturais com o estado paraense não são evidentes.

Ana Maria Carvalho, maranhense nascida em Cururupu, confirma essa proximidade com a cultura do estado vizinho. Vale a pena prestar atenção na riqueza de elementos que compõem sua narrativa de influências musicais. Podemos observar que há o convívio entre o popular e o erudito, dualidade que está presente nos processos de formação da identidade nacional, no campo da música e ainda enraizada em tantos campos artísticos:

Eu nasci no Maranhão, numa cidade que chama Cururupu, no Norte do Maranhão, mais pro lado de Belém. Mais pra lá do Pará, sabe? E sou filha de brincantes, trabalhadores e brincantes, toda minha família. Meu pai, ele era agricultor e ele era mestre de bumba-meu-boi, de tambor de crioula, de tamborinho... Tinha um tio, já da família da minha mãe, que era saxofonista. Tinha tia que era cantora, então eu cresci nesse ambiente de muita informação cultural, é... tios compositores, então toda minha família tem essa base da cultura popular e até um pouco da erudita. De erudito, meu tio - ele morreu muito cedo - esse saxofonista e me apagou a memória dele. E aí essa coisa, gente, eu sou uma pessoa muito melódica. Minhas composições têm muita melodia. E aí um dia assim pensando, eu falei: "gente de onde que vem isso?" E eu lembrava que quando o meu tio estava lá tocando, que eu pegava as partituras dele que voavam e trazia de volta e sempre ouvia muito ele tocar. Então isso está em mim também da infância, tanto como tambor de criola, o bumba meu boi, o... sabe.. o cacuriá... mas tem todo esse lado desse tio meu. (ANA MARIA).

O relato de Ana Maria, além de confirmar a ideia de diversidade e pluralidade musical do Nordeste, revela a mistura de influências populares com a referência erudita de seu tio. Essa informação abre as portas para discussões em torno do erudito e do popular, campos tão polarizados em diferentes extremos no Brasil. Para Rocha (2013, p.46):

A modernidade assistiu ao surgimento das categorias "erudito" e "popular" como trincheiras simbólicas que serviram, durante muito tempo, para diferenciar a produção cultural consagrada daquela incapaz de dotar os seus consumidores dos signos de distinção tão preciosos em uma sociedade de crescente mobilidade e anonimato.

Essa dualidade está diretamente ligada à discussão entre alta e baixa cultura proposta por Williams (2011). Desde os primeiros estudos sobre a formação musical brasileira é possível 
observar a defesa de uma alta cultura na valorização de obras eruditas. Chico Saraiva (2018) entende que os campos erudito e popular na música brasileira deveriam "conversar" mais e que o erudito poderia absorver e abrir maior diálogo com o popular.

Hoje, a musicologia brasileira e a própria sociedade avançaram na valorização da cultura popular, em relação ao período do primeiro livro de Almeida (1926) que deixava esses limites bem definidos. Com a expansão da indústria cultural e a proliferação de gêneros musicais populares, o contexto e os valores simbólicos em relação aos músicos e musicistas se alteram.

No trecho de entrevista a ser apresentado a seguir será possível identificar novamente a afirmação de diversidade de identidades e expressões artísticas entre músicos nordestinos, assim como perceber um pouco da tensa relação entre erudito e popular no campo da música. Adriano Costa, assim como os outros entrevistados e entrevistadas, foge do padrão estereotipado de músico nordestino (isto é, do sertanejo simples que toca músicas regionais). Nascido na Bahia, conta que desde criança ouvia seu pai tocar, ele era um grande admirador de jazz e da bossa nova:

No meu caso, lá em casa meu pai era músico, ele desde criança... meus irmãos... sempre teve essa influência, ver meu pai tocando... mas a gente começou mesmo a aprender música, teoria musical na banda. Bandinha de música, banda de interior, sul da Bahia. (...) lá na Bahia é axé, tá lá na rua, época de carnaval, verão... ir pra praia nos quiosques, lá era só axé, forró também, no meio do ano. Sempre essa época de músicas diferentes. Mas só que dentro de casa já tinha a influência do jazz, bossa nova, meu pai gostava. E sempre eu via a crítica do meu pai, sempre criticando a música lá da Bahia. Mas a gente tem bastante contato com essa música instrumental dentro de casa. É o primeiro contato desde pequeno, desde criança, eu lembro deles escutarem Frank Sinatra, Tom Jobim, então essa influência da música do meu pai foi bem forte pra gente poder escolher também esse caminho da música. (ADRIANO COSTA $)^{10}$.

O que vemos nos relatos apresentados são situações plurais de convívio com as múltiplas sonoridades nordestinas e para além delas, ou seja, a convivência com referências do erudito e com estilos de outras partes do mundo. Portanto, a formação desses músicos não se

10 Entrevista de Adriano Costa, concedida em 11 de maio de 2018. 
limitou a estilos tradicionais da região, mas estava exposta também a muitas outras possibilidades.

O mesmo ocorreu com músicos do Sudeste que tiveram contato com a musicalidade ampla da região Nordeste. Sobre suas experiências musicais no Nordeste, Chico Saraiva, que não é nordestino, relatou:

O Nordeste foi um caminho natural pra gente da A Barca atingir, foi natural seguir nesse sentido [...] A gente circulou sim nesse ambiente onde tem uma riqueza de ritmos e uma variedade. Só na Zona da Mata de Pernambuco, a quantidade de ritmos e manifestações que acontecem no plano musical é avassaladora, é incrível, a gente não consegue elencar numa frase curta, nem pretendo aqui fazer isso. Mas a maneira como essa riqueza e essa expressão tão variada de tantas frentes, de tantos gestos de corpo e melodias, ritmos, timbres de instrumentos de percussão, ou de sopro. Em Pernambuco, onde isso é tão rico. (CHICO SARAIVA) ${ }^{11}$.

A fala de Chico Saraiva revela dois pontos principais: a diversidade e a pluralidade de expressões musicais presentes na região Nordeste; e a forte influência das experiências pessoais de cada músico e cada musicista nos resultados de suas produções e performances musicais. Sobre a trajetória do músico:

Então, equacionar isso que é do pessoal e isso que é de uma região ou que caracterizam um tipo de música dá muito trabalho, a gente tem que cercar a questão por muitos lados para não correr o risco de ser simplificador, ser simplista e a nova geração faz isso quando chega e absorve, absorve o seu entorno e aquilo com que está em contato, sem deixar de ser aquilo que tanto pelo plano pessoal, aquela pessoa tem como marca especial enquanto músico, quanto no plano da origem possa ter como um músico que é proveniente de um estado nordestino. (CHICO SARAIVA).

A identidade nacional e as identidades regionais mostram-se, portanto, como conjuntos de valores que estarão sempre em disputa e abertos a negociações e apropriações que, dependendo do contexto e de toda complexa rede de variáveis culturais, se transformam e se atualizam, mantendo elementos que permanecem enraizados, mas sempre com a possibilidade de novas mudanças. E isso vale para a ideia de uma identidade musical nordestina.

${ }^{11}$ Entrevista de Chico Saraiva, concedida a Lucas Pulice, em 8 de fevereiro de 2019. 


\section{Nordeste: permanências e rompimentos na música}

Albuquerque Jr. (2009) aponta o movimento do tropicalismo como um exemplo bemsucedido de expressão artística que contribuiu para o questionamento da identidade nordestina e que conseguiu ampliar os horizontes e promover rompimentos.

Um conjunto de imagens e discursos construídos e acumulados durante décadas, referente ao universo nordestino, inclui alguns temas "regionais" de maior relevância: a decadência da sociedade açucareira, o cangaço, o coronelismo, a seca, a miséria, a migração e a saudade. Esses temas, que já estavam presentes na literatura popular. Esses temas da seca, do sofrimento e do "folclórico" são resgatados também na música nordestina. Segundo o autor, grande parcela dos artistas nordestinos anteriores aos tropicalistas se apoiava em discursos e imagens que fortaleciam os estereótipos (ALBUQUERQUE, 2016).

Foi na década de 1940 que surgiu para o Brasil o Luiz Gonzaga, principal nome responsável pela consagração da música nordestina. O rádio era o maior meio de comunicação de massas, de 1943 em diante, e se rendeu às graças do baião. Em pouco tempo, Luiz Gonzaga passou a ser considerado pela mídia e por grande parcela da população brasileira como o "rei do baião" ou o "criador da música nordestina". Sanfoneiro habilidoso que espalhou dezenas de sucessos pelo país, o conteúdo de boa parte de suas canções ${ }^{12}$ foi dirigido aos migrantes e tinha a seca do sertão como tema central. Suas músicas tornaram-se grandes sucessos nas rádios, no auge desse veículo como comunicador de massas e como um dos principais recursos do Estado para construir a integração nacional e encurtar as distâncias entre as regiões do país, colaborando para a imagem de unidade da nação (ALBUQUERQUE, 2009).

Além da música, o sotaque e as expressões de Luiz Gonzaga em entrevistas e letras colaboravam também para a construção das imagens e discursos que representam o Nordeste.

Surgiu, então, o Movimento Tropicalista, na década de 1960, um grupo que reunia artistas de diferentes frentes em um caldeirão cultural que misturava manifestações tradicionais com cultura pop, propondo inovações radicais na linguagem e estética. Nele, estavam envolvidos grandes nomes do teatro, cinema, poesia e artes plásticas, mas foi na música que o movimento eclodiu, em 1967, tendo como marco o Terceiro Festival de Música Brasileira,

\footnotetext{
${ }^{12}$ Luiz Gonzaga teve dois compositores parceiros com os quais escreveu a maior parte de suas canções, são eles Humberto Teixeira e José Dantas.
} 
organizado pela TV Record. Os principais personagens foram Gilberto Gil, Os Mutantes (com Rita Lee, Arnaldo Baptista e Sérgio Dias) e Caetano Veloso.

Para Albuquerque (2009), o Tropicalismo nos permite pensar no rompimento da cultura em termos de nacional ou regional. Ao não representar o nordestino no sentido consagrado, o movimento propõe novos olhares para a região e para a diversidade dos nordestinos.

No artigo Vede Sertão, verdes sertões: Cinema, fotografia e literatura na construção de outras paisagens nordestinas, Albuquerque (2016) aponta artistas e pensadores que romperam com as imagens clichês que por tanto tempo representaram a natureza e a realidade nordestinas:

Um discurso de distanciamento crítico em relação às imagens e discursos que sustentam a ideia de região Nordeste emerge, inclusive, elaborado por intelectuais que não tendo nascido na região e vindo para nela trabalhar, têm condições subjetivas de se distanciarem das formulações regionalistas. Livros como Elegia para uma Re(li)gião, do economista Francisco de Oliveira, publicado em 1977, A Questão Nordeste, do sociólogo Silvio Maranhão e $O$ Regionalismo Nordestino, da historiadora Rosa Maria Godoy Silveira, publicados em 1984, O Nordeste e a Questão Regional, do geógrafo Manuel Correia de Andrade, publicado em 1988, O Mito da Necessidade: discurso e prática do regionalismo nordestino, da socióloga Iná de Castro e $O$ que faz ser nordestino? da socióloga Maura Penna, publicados em 1992, se constituem em importantes contribuições para o afastamento crítico em relação ao discurso regionalista nordestino. (ALBUQUERQUE, 2016, p. 8).

As trajetórias e produções musicais dos entrevistados apontam para esse caminho da diversidade e da pluralidade entre musicistas nordestinos e nordestinas e para o afastamento dos regionalismos. Não se trata de definir a "verdadeira representação do Nordeste", mas de tentar entender a formação e a reprodução dessa tradição inventada em torno dele e como ela opera, seja fora ou dentro de suas fronteiras (ALBUQUERQUE, 1994, p.92). Precisamos nos deslocar desses mecanismos engessados. Os entrevistados desta pesquisa reforçam a pluralidade musical para além do Nordeste do baião e da seca.

Um ponto das entrevistas que chamou a atenção foi a pouca menção a Luiz Gonzaga. Apenas Ana Maria Carvalho e Nathalia Ferro o citaram. Curiosamente, são justamente as duas que se disseram mais influenciadas pela região Norte, fato que colabora ainda para o deslocamento do que é comumente assumido como a nordestinidade. 
Jackson Ricarte é do sertão cearense e toca viola caipira, instrumento difundido principalmente no interior de São Paulo e em estados do Centro-Oeste e presente também em algumas regiões do Sul. Esse fato por si só rompe com a tradição inventada em torno de músicos nordestinos, afinal dentre suas referências e inspirações estão Almir Sater (MS) e Sérgio Reis (SP): “Antes de fazer as malas, já ouvia Luiz Gonzaga e o xará Jackson do Pandeiro, ídolos cuja paixão passou a dividir com Tião Carreiro e Almir Sater, dentre tantos outros compositores e cantores, vivendo na nova cidade" $"$.

Sobre sua produção artística, Ricarte ${ }^{14}$ explica que na forma de cantar e nos fraseados da viola é possível perceber elementos do universo nordestino, mas o resultado é consequência de misturas na sua trajetória e da bagagem de sua carreira.

Um trecho da fala do entrevistado Passarinho também indica a tendência atual de misturar gêneros tradicionais a elementos da cultura pop e urbana:

[...] a gente começou a fazer um som diferente do que a cidade estava acostumada, mas, ao mesmo tempo, em alguns pontos a gente conseguia ver que as pessoas já conheciam, já gostavam muito de Nação Zumbi, muitas pessoas de Jacareí, de Taubaté, de Pinda... já gostavam, já tinham contato direto com essa vertente da música mangue beat, da música brasileira, é... da ciranda, do maracatu, do afoxé, do ileaê, puxadas pro dub, pro rock, misturado com psicodelia, que é o que a galera do nordeste faz, na sua grande maioria das bandas que tem hoje assim... os caras pegam uma vertente cultural própria, por exemplo o coco, a embolada e bota uma pitada de música atual, o rock, o dance, o dub, o reggae jamaicano... (PASSARINHO).

Passarinho afirma que compositores e compositoras nordestinas têm buscado essa releitura de ritmos da cultura popular alinhada a novidades contemporâneas. Mendonça (2007, p. 1), ao refletir sobre o Manguebeat, afirma que "as culturas urbanas contemporâneas são moldadas pelo impacto de fluxos transculturais e de processos de transformação das formas de relacionamento com as tradições".

\footnotetext{
13 Biografia de Jackson Ricarte. Disponível em: http://www.jacksonricarte.com.br/?link=biografia, Acesso em: 05 dez. 2019.

${ }^{14}$ Entrevista de Luiz Felipe "Passarinho", concedida a Lucas Pulice, em 18 de setembro de 2017.
} 
Essa não é uma tendência inédita, a mistura entre o tradicional e o popular urbano pode ser vista na geração de nordestinos que se destacou, a partir dos festivais da década de 1960, e que gravaram sucessos posteriormente, como Caetano Veloso, Alceu Valença, Geraldo Azevedo ou Fagner. Segundo Saraiva (2014 p. 6):

Os artistas oriundos do Nordeste (na década de 70) trazem uma nova roupagem para a $M P B$, eles têm grande influência de cantores já consagrados como Luiz Gonzaga, mas com um diferencial: a trajetória de vida. A maioria desses artistas pertencia a classe média urbana, quase todos com formação universitária.

Nathalia Ferro destaca essa mistura entre o tradicional e o popular na cena paulistana. Em um trecho de sua entrevista reflete sobre esses movimentos que acontecem no cenário paulistano e que envolvem muitos artistas nordestinos:

Eu cheguei aqui em São Paulo em um momento em que a música, o nicho musical do qual eu faço parte estava bebendo diretamente das fontes do meu estado. Entendeu? Então assim, se tu for observar a maioria dos trabalhos que tão aí fazendo frente na cena underground mais "top" de São Paulo, a gente tem o Kiko Dinucci com a Juçara Marçal e tem também a Elza, eles bebem referências ali da Fanti Ashanti ${ }^{15}$, do Pai Euclides, sabe? Tem muita gente que tá aí utilizando células de Tambor de Crioula pra fazer música. O próprio CD do Instituto, na primeira faixa eles falam do tambor de crioula e tocam algo ali parecido. Mas fora o Estado do Maranhão, eu notei que a música tava muito imbuída desse caráter afrodescendente, sabe, que é minha base musical, é daí desse lugar, percussivo, tradicional, ancestral, entendeu? E aí quando eu cheguei tava rolando, era isso, aqui em São Paulo. Tava rolando que a maior parte dos artistas tavam de olho na musicalidade dos terreiros [...]. Então, de repente, começou a explodir mesmo o rap, começou a explodir mesmo o funk, começou a explodir mesmo as músicas de terreiro, sabe, a galera começou a aparecer nesses corpos tanto de artistas paulistanos quanto nos "nordestes", dos nordestinos que tão aqui fazendo música. (NATHÁLIA FERRO) ${ }^{16}$.

Ao mesmo tempo, a cantora afirma o desejo de incorporar mais diretamente os ritmos da cultura tradicional do Maranhão, das matrizes afrodescendentes em seu trabalho. Em sua

\footnotetext{
${ }^{15}$ Conhecida casa de Candomblé e Tambor de Minas de São Luís (MA).

${ }^{16}$ Entrevista de Nathalia Ferro, concedida em 5 de novembro de 2018.
} 
fala, tange também a visão do nordestino como o "outro", o "exótico", reforçando sua posição além dos estereótipos e motivada a passar adiante a ideia de outros nordestes:

Mas, por outro lado, fico no anseio de talvez resgatar na minha música ou experimentar alguma coisa que seja originalmente do meu estado, porque é isso, se o Kiko Dinucci pode fazer no som dele. Pode porque é brasileiro, porque deve, né? Porque música tem é que fazer. Eu também posso fazer porque eu nasci e me criei lá, entendeu... Então, me dá uma vontade maior de trazer isso pra cá porque a gente chega meio estrangeiro, a gente fica meio achando que não vai ser compreendido, que não vai ser entendido. Só que para longe do exotismo, que também existe, de tu chegar e a galera ficar "Nossa, você é um papagaio diferente". "Fala umas palavra nova", né? Fora desse lugar que eu acho um pouco enfadonho. (NATHÁLIA FERRO) $)^{17}$

Nathalia diz que esses recortes de seu estado natal vêm sendo descobertos agora porque os dois nomes de maior expressão nacional, originais da capital maranhense, são a Tribo de Jah - banda de reggae - e o cantor Zeca Baleiro - ligado ao universo da MPB. Isto também vai ao encontro da imagem de diversidade cultural nordestina que o conjunto dos entrevistados representa.

Os músicos conterrâneos de Luiz Gonzaga, ou seja, pernambucanos, não relataram nenhuma experiência musical ligada ao baião. Passarinho, em seu mais recente projeto, mistura a música brega, como elemento nordestino, com influências internacionais urbanas como o Reggae e o Dub. Podemos então perceber certa tendência de movimentos contemporâneos musicais incorporarem características resgatadas de culturas tradicionais, alinhadas a gêneros difundidos pela indústria cultural recente, resultando em novas linguagens, como foi na proposta tropicalista.

Leano é cearense e toca saxofone. Sua formação no instrumento foi muito ligada ao jazz e à música europeia de orquestras. No entanto, ele afirma que o baião sempre esteve presente na sua escuta, principalmente antes de aprofundar seus estudos no campo instrumental. Mesmo assim, refere-se ao gênero como uma paisagem sonora de sua lembrança em Fortaleza. Na sua produção artística, além da banda do CTA, ele mistura o baião à linguagem instrumental:

17 Entrevista de Nathalia Ferro, concedida em 5 de novembro de 2018. 
Mas eu escutei bastante o baião, e na música instrumental tenho composição que é nesse ritmo, do baião, que é muito lá da minha área, foi muito presente na minha vida. Essa parte do junino, do folclórico, do baião é, tem muito isso em mim também, apesar de não estar sempre ouvindo mais, mas ainda é bem presente. (ANDRÉ LEANO ${ }^{18}$ ).

As misturas, influências e mais a trajetória individual de cada entrevistado criam nova identidade musical, que não está nem na raiz de sua origem nem totalmente nas novas influências adquiridas, está em outro lugar, híbrido, que carrega todos os sentidos.

Sobre essas misturas entre o que é tradicional de sua terra natal, o que é urbano e o que é adquirido ao longo da trajetória pessoal e musical de cada um, Chico Saraiva citou o compositor, cantor e violonista paraibano Chico César:

O jeito de Chico César tocar violão que eu vi outro dia, que é meu parceiro, eu sou atento a isso há muito tempo. Aquilo tem um background que remete diretamente à tradição nordestina. Há quanto tempo o Chico tá aqui? Ele tá aqui na batalha já há muito tempo, uma grande estrela, um grande músico que veio e fez sua carreira. E esse processo de vir a fazer sua carreira faz parte da música dele, universaliza aquelas informações que tem sim uma origem muito marcadamente nordestina, no caso dele. Cada artista deve ser olhado pelo artista que é. (CHICO SARAIVA) ${ }^{19}$.

Assim como no Tropicalismo, muitos dos musicistas do Nordeste das novas gerações, inclusive os entrevistados que participaram dessa pesquisa, dão à vivência nordestina outro lugar. Esse novo lugar é muito mais diverso e distante do espetáculo de miséria e de carência primitiva da dualidade sertão/cidade grande que foi difundido antes do movimento da Tropicália. A produção tropicalista vai na contramão do discurso regionalista, do folclórico como pitoresco, vai contra a reprodução da hierarquia de saberes e poderes (ALBUQUERQUE, 2009).

$\mathrm{Na}$ esteira das conquistas do Tropicalismo, Marquinho da Luz, baiano que mora atualmente em São José dos Campos, é um exemplo dessa globalização de significados e valores. Descoberto para o processo de seleção do Cirque du Soleil por meio de seus vídeos na

\footnotetext{
${ }^{18}$ Entrevista concedida a Lucas Pulice, em novembro de 2018.

${ }^{19}$ Entrevista de Chico Saraiva, concedida em 8 de fevereiro de 2019.
} 
plataforma Youtube $^{20}$, o percussionista realiza atualmente turnês com a rede circense pelo mundo todo, ao lado de uma equipe internacional, misturando elementos percussivos do universo baiano à linguagem musical do espetáculo. Ao longo de sua entrevista, Marquinho afirmou que abriu seu leque de ritmos e gêneros, desde sua mudança para São José dos Campos, mas que se manteve "sempre com um pezinho na essência", o que acha importante para sua musicalidade.

Essa apropriação de elementos tradicionais de seu estado de origem por parte de artistas nordestinos contemporâneos, é um claro afastamento da ideia de conservação de valores regionais e tradicionais do Manifesto Regionalista de Gilberto Freyre, de 1926 (FREYRE, 1996), no qual procedeu à defesa da "tradição cultural nordestina", aquela que aproximava a região do seu passado rural e que estaria inserida no âmbito da discussão sobre tradição e modernidade da primeira fase do Modernismo.

Para os artistas aqui entrevistados a utilização de elementos tradicionais é atualizada e misturada com diferentes vertentes, frutos da trajetória de cada músico e musicista. Eles não se apresentam mais no lugar do pitoresco, mas sim no lugar do atual, da tendência. O resgate e a atualização de sentidos funcionam como dispositivos de transformação imagético-discursiva acerca do Nordeste e da música nordestina.

Segundo Janete Rodrigues (2009),

Os diversos Nordestes rurais e urbanos de hoje se encontram integrados aos contextos nacional e mundial por modernos sistemas de comunicação e informação capazes de estabelecer padrões locais, nacionais e globais de comportamentos, valores culturais e regras sociais que intervêm nos processos de transformações identitárias culturais das sociedades nordestinas atuais mediante enfrentamentos e jogos de negociações nas construções dessas identidades. Porém, nos questionamentos sobre as cristalizações observadas acerca desses estereótipos identitários no contexto atual acerca do Nordeste e dos nordestinos, é importante considerarmos que vivemos um momento marcado pelas dinâmicas e fragmentações das identidades culturais locais, nacionais e globais onde se fundem aquilo que é da ordem do local e do global.” (RODRIGUES, 2009, p. 11).

\footnotetext{
${ }^{20}$ Disponível em: https://www.youtube.com/channel/UCYTgkT2ODcz-4VGCg3a8wSA, acesso em 26/dez/2019.
} 


\section{Observações finais}

Musicistas nordestinos em São José dos Campos são nordestinos, mas também são do seu estado, da sua cidade e do mundo. Eles tocam estilos diversos, convivem com cenas musicais nacionais e internacionais e transitam pelas possibilidades sonoras infinitas que lhes são apresentadas. Nesse processo, incorporam elementos tradicionais da sua origem regional e percebem isso em colegas com trajetórias similares. Ou seja: eles acionam a identidade nordestina, pois sentem algo dela em sua vida. Mas também questionam o que seria essa generalização identitária e dão a ela novos significados.

O que fazem é algo híbrido: não é tradicional, mas é um pouco; não é só moderno, pois incorpora algum elemento do tradicional. Não é nordestino, porque o Nordeste é uma invenção. Mas também absorve algo dessa identidade. O que vemos é algo novo transformando estereótipos imagético-discursivos construídos no passado de forma rígida.

Novas expressões artísticas de origem nordestina estão sendo produzidas e circuladas em grande escala em uma cidade do Vale do Paraíba que oscila entre as culturas do eixo RioSão Paulo. É preciso olhar para essa ressignificação dos discursos e paisagens do Nordeste para que os questionamentos cheguem aos ouvidos das pessoas e aos meios de comunicação em massa e para que o rompimento dos estereótipos seja cada vez mais possível.

\section{Referências bibliográficas}

ALBUQUERQUE JR., Durval Muniz de. O Engenho Anti-Moderno: A invenção do Nordeste e outras artes. 1994. Tese (Doutorado no Departamento de História), Instituto de Filosofia e Ciências Humanas da Universidade Estadual de Campinas, Campinas.

ALBUQUERQUE JR., Durval Muniz de. Vede Sertão, Verdes sertões: Cinema, fotografia e literatura na construção de outras paisagens nordestinas. Fênix - Revista de História e Estudos Culturais, vol. 13, ano XIII, n. 1, jan/jun 2016. Disponível em: http://www.revistafenix.pro.br/vol37-a01.php

AlbuQuerQue JR., Durval Muniz de. A invenção do Nordeste e outras artes. $4^{\mathrm{a}}$ ed. Recife: FJN/ Massangana. São Paulo: Cortez, 2009. 340 p.

ALMEIDA, Renato. História da música brasileira. Rio de Janeiro: F. Briguiet, 1926. 
FREYRE, Gilberto. Manifesto Regionalista. $7^{\mathrm{a}}$.ed. Recife: FUNDAJ/Massangana, 1996. p.4775. Disponível em: http://www.ufrgs.br/cdrom/freyre/freyre.pdf, Acesso em: 26 dez. 2019.

MENDONÇA, Luciana. Música pop(ular), diversidade e identidades o manguebeat e outras histórias. Publicações Oficinas CES/UC, Coimbra. 2007. Disponível em: https://www.ces.uc.pt/publicacoes/oficina/ficheiros/275.pdf, Acesso em: 05 dez. 2019.

ROCHA, Maria Eduarda da Mota. Notas sobre a dualidade entre "alta" e "baixa" culturas no campo cultural brasileiro. Ideias, n. 7. 2013. Disponível em: https://periodicos.sbu.unicamp.br/ojs/index.php/ideias/article/view/8649380

RODRIGUES, Janete de Páscoa. Mídias e identidades culturais nordestinas: transições entre estigmas e concretudes. Intercom - Sociedade Brasileira de Estudos Interdisciplinares da Comunicação. XI Congresso de Ciências da Comunicação na Região Nordeste, Teresina, $2009 . \quad$ Disponível em: http://www.intercom.org.br/papers/regionais/nordeste2009/resumos/R15-0177-1.pdf SARAIVA, Daniel. Sotaque: a memória de infância de três artistas nordestinos. Revista de História Oral. $\quad$ v. 20. n. 1. 2017. Disponível em: https://revista.historiaoral.org.br/index.php?journal=rho\&page=article\&op=view \&path\%5B\% $\underline{5 \mathrm{D}=682}$

SARAIVA, Daniel. Vento Nordeste: A explosão da música popular Nordestina nas décadas 1970 e 1980 através da memória de Terezinha de Jesus. Anais do II Seminário Internacional História do Tempo Presente, out. 2014, Florianópolis, 2014.

TROTTA, Felipe. Som de cabra-macho: sonoridade, nordestinidade e masculinidades no forró. Comunicação, mídia e consumo. Ano 9, vol. 9, n.26, p.151-172. São Paulo, nov. 2012. Disponível em: http://revistacmc.espm.br/index.php/revistacmc/article/view/349

WILLIAMS, Raymond. Cultura e sociedade: de Coleridge a Orwell. Petrópolis, RJ: Vozes, 2011. 